This item was submitted to Loughborough's Research Repository by the author.

Items in Figshare are protected by copyright, with all rights reserved, unless otherwise indicated.

\title{
Patterning servo-mechanism for a circular warp knitting machine
}

PLEASE CITE THE PUBLISHED VERSION

https://doi.org/10.1016/S0957-4158(00)00039-8

\section{PUBLISHER}

(c) Elsevier

\section{VERSION}

AM (Accepted Manuscript)

\section{PUBLISHER STATEMENT}

This work is made available according to the conditions of the Creative Commons Attribution-NonCommercialNoDerivatives 4.0 International (CC BY-NC-ND 4.0) licence. Full details of this licence are available at: https://creativecommons.org/licenses/by-nc-nd/4.0/

\section{LICENCE}

CC BY-NC-ND 4.0

\section{REPOSITORY RECORD}

Mermelstein, Sylvia P., Darren A. Hale, Memis Acar, Michael R. Jackson, and Kevin Roberts. 2019. "Patterning Servo-mechanism for a Circular Warp Knitting Machine". figshare. https://hdl.handle.net/2134/26963. 


\title{
Patterning Servo-Mechanism for a Circular Warp Knitting Machine
}

\author{
S. P. Mermelstein, D. Hale, M. Acar, M.R. Jackson, K. Roberts* \\ Department of Mechanical Engineering, Loughborough University, UK \\ *Tritex International Limited, Barwell, Leics, UK
}

\begin{abstract}
Warp knitting is always performed on flat (linear) knitting machines. A circular warp-knitting machine is recently made possible by using a novel concept of a conical needle bed and patterning cams with enclosed cam followers to drive the patterning rings. This also requires a mechanical linkage to transmit the motion from the patterning cam to the patterning rings, which is prone to vibration at undesirable levels. A new generation design replaces the mechanical cam and linkage with highspeed, AC brushless servomotors, enabling limitless, precision patterning possibilities. A method of selecting servomotors based on minimising the power required to perform the fastest motion required for a given application is reported. This method ensures cost minimising by selecting the smallest servomotor suitable for a given application. A circular warp-knitting machine using servomotor to drives selected using the method reported is designed, built and successfully tested.
\end{abstract}

\section{Introduction: Patterning Mechanism Overview}

Flat warp knitting machines employ three main mechanisms to produce stitches. Namely, a knitting mechanism that reciprocates the needles vertically, a swinging mechanism to move the yarns from the front to the back of the needles and a shogging mechanism to produce the overlaps and underlaps parallel to the plane on which the needles are laid.

A pattern consists of a chain of different length underlaps and hence the flexibility of the machine patterning depends on the ease of modifying the movements performed by its shogging mechanism and the length of the pattern chain.

The warp knitting needle cycle for a flat knitting machine can be described as comprising six stages. Starting with the needles at their highest position and having the 
previous loops round their stem, in stage (1) the yarns are swung from the back to the front of the needles. At stage (2), the overlap, a thread is laid under the hook of the needle by performing a sideways shog from one needle space to the next. The yarns are then swung to the back of the needle in stage (3). The needles then start to move downwards, the old loops are caught under each needle latch and cause the latches to close. The needles continue moving down until the old loops reach the top of the needle, are cast-off (stage (4)) and pulled by fabric tension. At stage (5), the underlap, the threads are shogged again, this time behind the needles. As the needles rise again (stage (6)), the threads in the hooks open the latches and become the next loops.

On a circular machine, the yarns are threaded through radially perforated rings. The shogging movement becomes a rotation of these rings and a pattern chain comprises a number of rotational movements of the rings in synchronisation with the main mechanism responsible for reciprocating the needles vertically (see Figure 2).

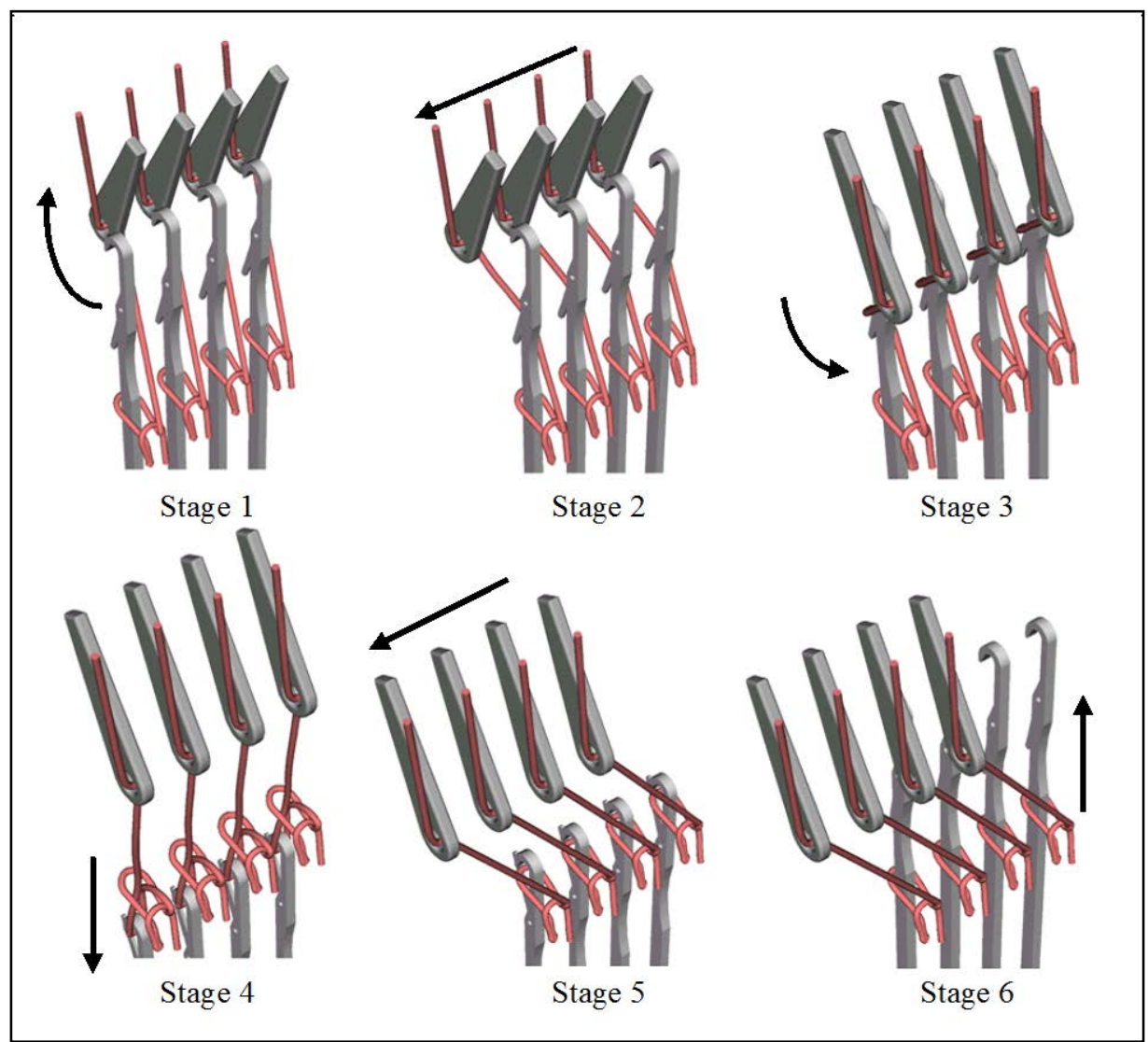

Figure 1. Illustration of warp knitting steps 
The rings must perform two distinct rotations and two dwells during a machine cycle. The direction and amplitude of the rotations will depend upon the fabric structure being created. However, an overlap will always be carried out over one needle only, while an underlap can be under several needles and could therefore require a larger rotation of the ring.

The larger the number of rings, the greater the patterning possibilities. However, the amount of space to place them and the complexity of the yarn paths generally restricts the number of patterning rings present in a machine.

\section{System requirements}

The first design prototype was used as an industrial knitting machine to produce packaging fabrics, stockings bandage materials and other technical textiles. A product design specification for a machine to cover all these markets was carried out in order to establish the end products' requirements. It was found that most applications would not require more than a 4 -needle underlap. In addition, that the

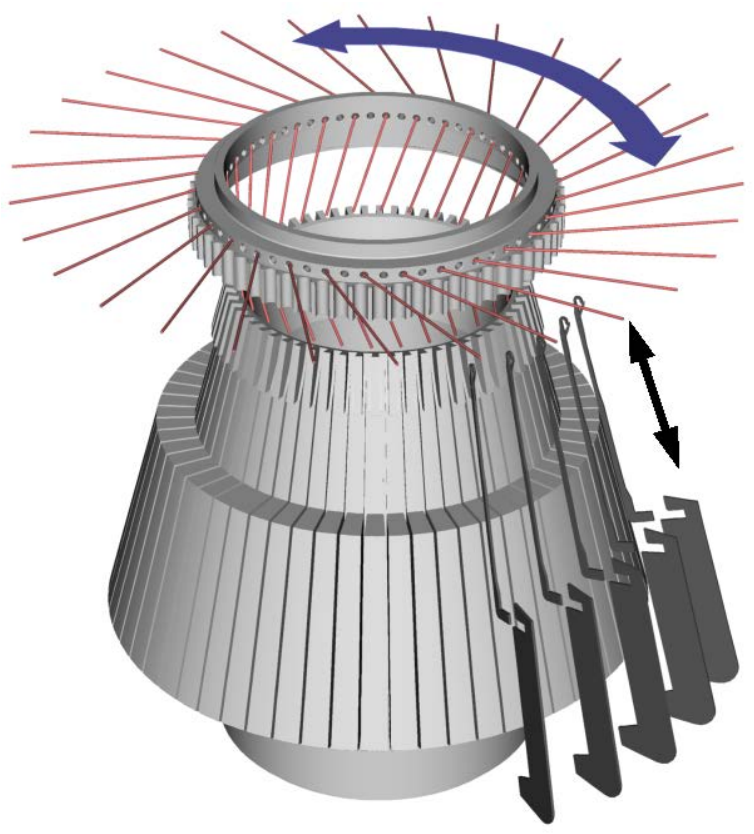

Figure 2. A patterning ring and needles on a circular warp knitting machine

minimum gauge (number of

needles per inch) in the relevant applications was 4 . The cylinder diameter is not critical for the netting applications; this varies in the range of 75 - $100 \mathrm{~mm}$ for the stockings application and it varies widely for medical applications. For the first prototype, a 75 mm diameter cylinder was used. For this size cylinder, 4 needle spaces at 4 needles per inch are equivalent to a 38 degrees of the cylinder. A 4-needle underlap will probably 
require a rotation of 8 needle spaces, which is ec

It was therefore decided to set as system re must be able to perform a rotation of up to $80 \mathrm{de}$

The fabric designer can alter the portion patterning ring movements (underlap and over warp-knitting machine, one third of the machir the needles' movement. This leaves two thir underlap and overlap; $120^{\circ}$ each.

Assuming that the maximum speed of the $m_{c}$ takes place in $60 \mathrm{~ms}$. This leaves only $20 \mathrm{~ms}$ to overlap rotation.

\section{Mechanical Solution}

The patented patterning mechanisms (Boren mechanically controlled, use two patterning rinধ a maximum pattern length of twelve machine , cycles is due to space limitation. A larger numl require a larger cam, but the space in which the

The main progress achieved with the mechar were; 1) the use of enclosed cam followers in vibration effects created when using open manufacturing process of the patterning cams $b$ the milling programs of the patterning cam, and by using cycloidal profiles for each segment.

Cycloidal profiles are known to give the (Erdman and Sandor, 1991) when compared to they provide three finite derivatives of displacer by;

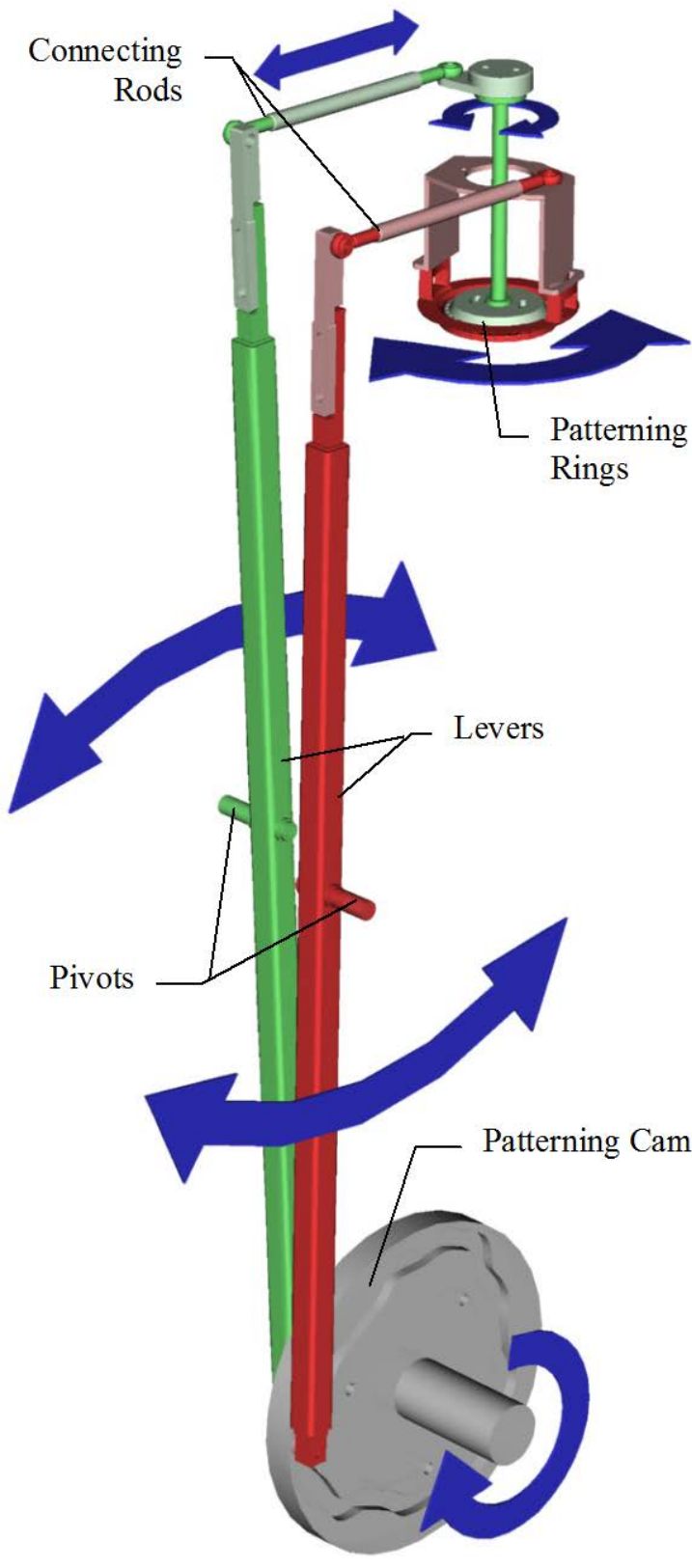

Figure 3. Mechanical Design Patterning mechanism 
$y=\frac{\phi}{\beta} L-r \cdot \sin \left(\frac{2 \pi}{\beta} \phi\right)$

Where,

$\begin{array}{lll}\mathrm{y} & : & \text { Displacement } \\ \phi & : & \text { Cam angle } \\ \beta & : & \text { Angle of cam rotation } \\ & & \text { during rise } \\ r & : & \frac{L}{2 \pi} \\ \mathrm{L} & : & \text { Maximum rise amplitude }\end{array}$

The only drawback to using this type of profile for the current application is the non continuous jerk curve at the end points of each motion. That is, at the point where the rise (or return) period ends and the dwell period begins. This is because the third derivative of the displacement is not zero at the end point, whereas that of a dwell is. If necessary, the motion curves could be further optimised by using polynomial profiles to ensure that the displacement and its three derivatives are continuous throughout.

A tailor made computer application was developed to create the cam profile program, which is then downloaded into a NC milling machine. Once on the knitting machine, the cam in motion was filmed using a high-speed video recorder (200 frames per second). There was no excessive vibration of the follower in the cam-track; even when viewed frame by frame it was seen that the follower did not leave the side of the track on which it was rolling.

The mechanical system converts a translational motion created by the patterning cam into a rotation of the patterning ring by means of a number of pivots and mechanical linkages (See Figure 2). The configuration and length of the linkage components depend on the physical space available and the dimensions of the machine elements. For example, in order to create a longer pattern by circular motion of the ring, while maintaining appropriate pressure angles in the cam, the baseline radius of the cam must increase.

Although the cam-follower mechanism ran smoothly, the high-speed video showed excessive vibration of the patterning rings. The contrast between the smooth running of 
the cam follower and irregular motion of the rings suggests that the latter is created by the elasticity of the mechanical linkages. The speed of the machine would therefore always be constrained by the mechanical properties and the dimensions of the linkages.

This mechanical design proved the circular warp knitting mechanism concept to be feasible. However, a design that allowed for more patterning flexibility and ultimately higher operatinal speeds was required in order to manufacture the more complex fabric designs used in the medical and stockings industries.

\section{Servo-controlled Solution}

An entirely new approach to the patterning mechanism problem was to control the rings using servomotors. Although a more costly solution, it has the potential of creating pattern chains that are only restricted by the size of the memory of the hardware used (ie hundreds of machines cycles rather than 12) and reducing the time and parts required to change from one pattern to another.

In addition, a servomotor would produce a rotational motion, when coupled via timing belts and pulleys could drive the patterning rings directly. There is no need for the mechanical transformation of translational motion to a rotational one that would have been required if other electronically controlled linearly actuated mechanical devices were used, such as linear pneumatic actuators.

Servomotors were selected over stepper motors because of the speed of reaction and position control requirements given by the knitting application.

This paper relates to the servo control of the patterning mechanism only. However, the main knitting mechanism, that is, the one responsible for the needle motion could also be servo-controlled giving further control over the synchronisation between needles and yarns. Yao et al, (2000) proposes a method to improve the motion characteristics of a cam follower by controlling the cam speed using servodrives. 


\section{Motor Selection}

Advances in high-speed applications are out-pacing advances in the control performance of servo drives. To close this gap, improved control are being developed and the designer has more choice in motors drives and motion controllers. Research devoted to the optimisation of the control loop used by the servomotor is beyond the scope of this paper and generally not within the timescale available to the designer for motor selection. Iwasaky et al (1996), for example, presents a high-accuracy trajectory-control method and its auto-tuning.

In the area of servo-drives used in high-speed machinery to replace traditional mechanical linkages (such as gears or belts), Beaven et al (1995) show that a reduction of cycle time is made possible by the application of set-point gain scheduling to high-speed independent drives. This involves the transition from one controller to another at a set point in the cycle by changing the gain values within the motion.

The main parameters involved in the selection of a servomotor are the torque required by the system (including the servomotor itself) and the speed at which the motor will run. Different angular velocity profiles can be used to perform a given rotational movement within a set time.

Using a triangular speed profile (see Figure 4),

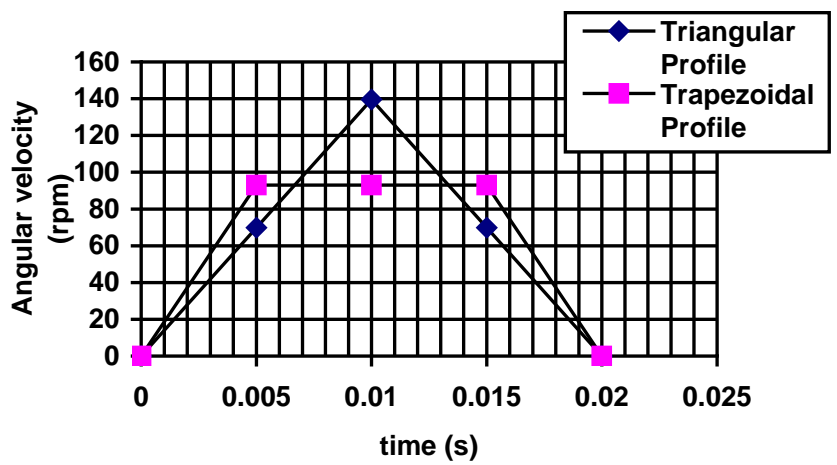

Figure 4. Motor Requirements 


$$
\begin{gathered}
\theta=\frac{\omega_{\max } \cdot t}{2} \\
\alpha=\frac{\Delta \omega}{\Delta t}=\frac{\omega_{\max }}{t / 2}=\frac{4 \theta}{t^{2}}
\end{gathered}
$$

The minimum angular acceleration the system would require is

$$
\alpha=\frac{4 \theta}{t^{2}}=\frac{4 \cdot(1.396 \mathrm{rad})}{(0.02 \mathrm{~s})^{2}}=13963 \mathrm{rad} / \mathrm{s}^{2}
$$

Which will reach an angular velocity of

$$
\omega_{\max }=\frac{2 \theta}{t}=\frac{2 \cdot(1.139 \mathrm{rad})}{0.02 \mathrm{~s}}=139.6 \mathrm{rad} / \mathrm{s}=1333 \mathrm{rpm}
$$

in $10 \mathrm{~ms}$.

If the time allowed for accelerating and decelerating is reduced, the speed curve will turn into the trapezoidal shape shown (see Figure 4); the acceleration needed would increase as would the torque and power requirements. The angular velocity, however, would decrease. The area below both curves is the same as it represents the angular position achieved after the displacement. The maximum velocity requirement is plotted in Figure 5 as a function of acceleration time.

$$
\begin{aligned}
& \theta=\omega \cdot t_{a c c}+\omega \cdot\left(t_{\text {total }}-2 \cdot t_{a c c}\right) \\
& \therefore \omega=\frac{\theta}{\left(t_{\text {total }}-t_{\text {acc }}\right)}
\end{aligned}
$$




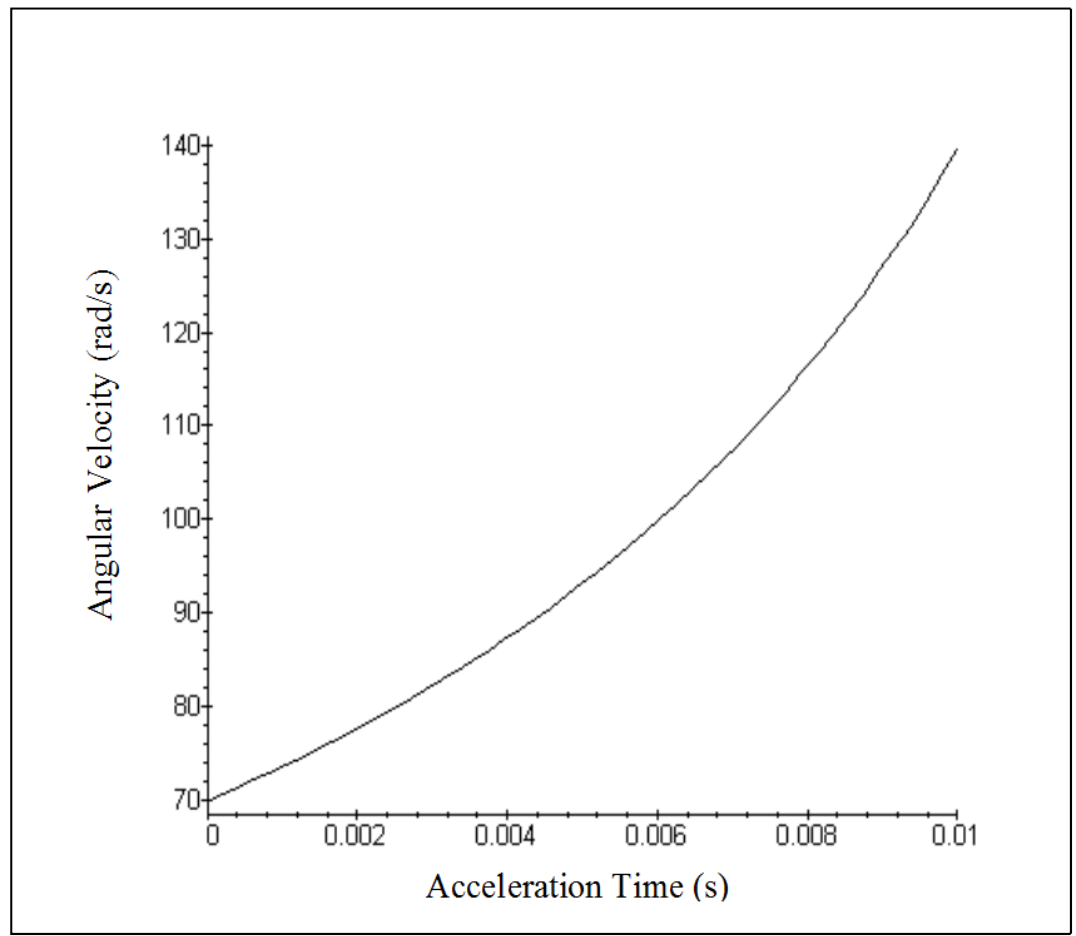

Figure 5. Time required to reach the maximum angular velocity

The acceleration required to reach the maximum angular velocity in $t_{a c c}$, for a given trapezoidal profile, is equal to $\alpha=\omega / t_{a c c}$. The torque requirements of the servomotor depend on the acceleration and the total inertia of the system (see Figure 6):

$$
T=I_{\text {TOTAL }} \cdot \alpha=\left(I_{\text {motor }}+I_{\text {load }}\right) \cdot \alpha=\left(I_{\text {motor }}+I_{\text {load }}\right) \cdot \frac{\omega}{t_{\text {acc }}}
$$




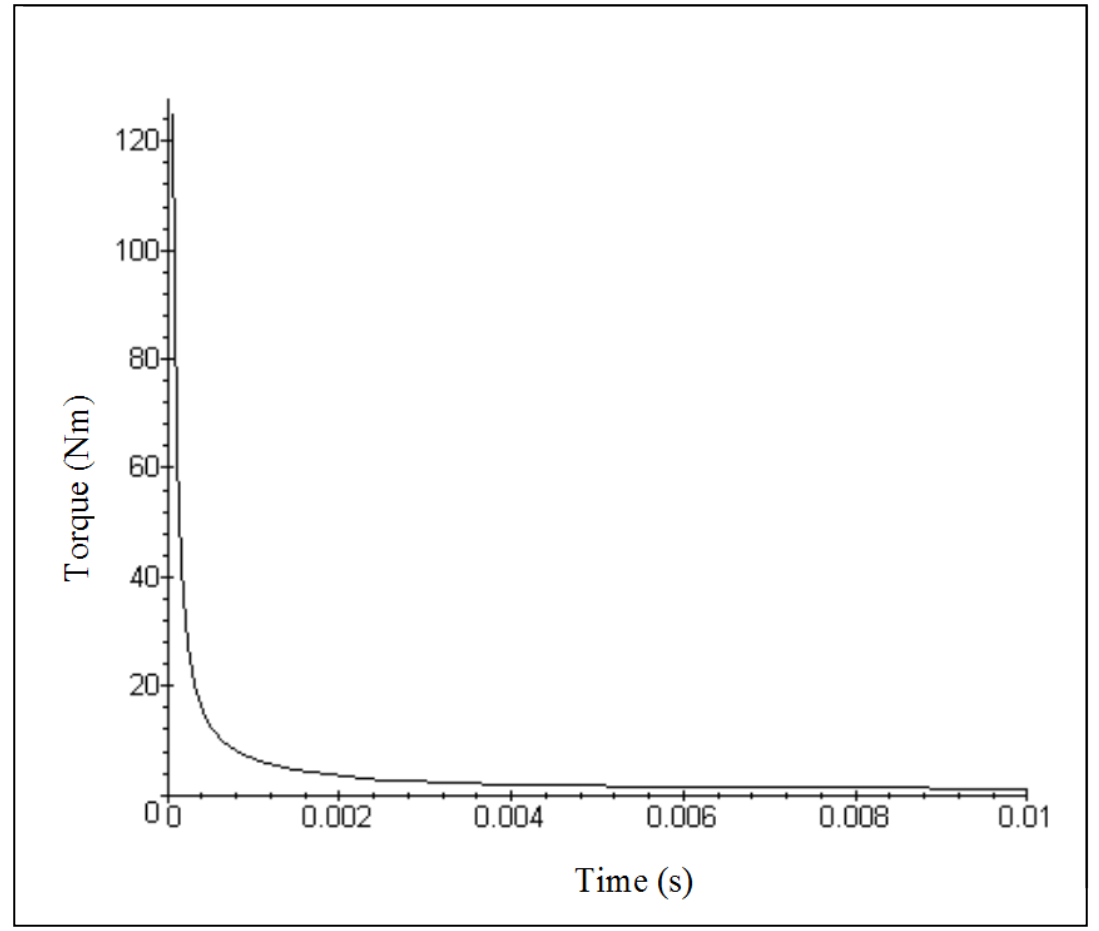

Figure 6. Torque required to reach the maximum angular velocity

\section{Rearranging (3) and}

(4), we can obtain an expression for Torque in terms of angular velocity;

$$
T=\frac{I_{\text {TOTAL }} \cdot \omega^{2}}{(\omega \cdot t-\theta)}
$$

Physical motor size (and rotor inertia) is directly proportional to power capability. In order to obtain the smallest motor capable of fulfilling the system requirements, the power used to perform the move must be minimised. The power requirement being;

$$
P=T \cdot \omega=\frac{I_{T O T A L} \cdot \omega^{3}}{(\omega t-\theta)}
$$




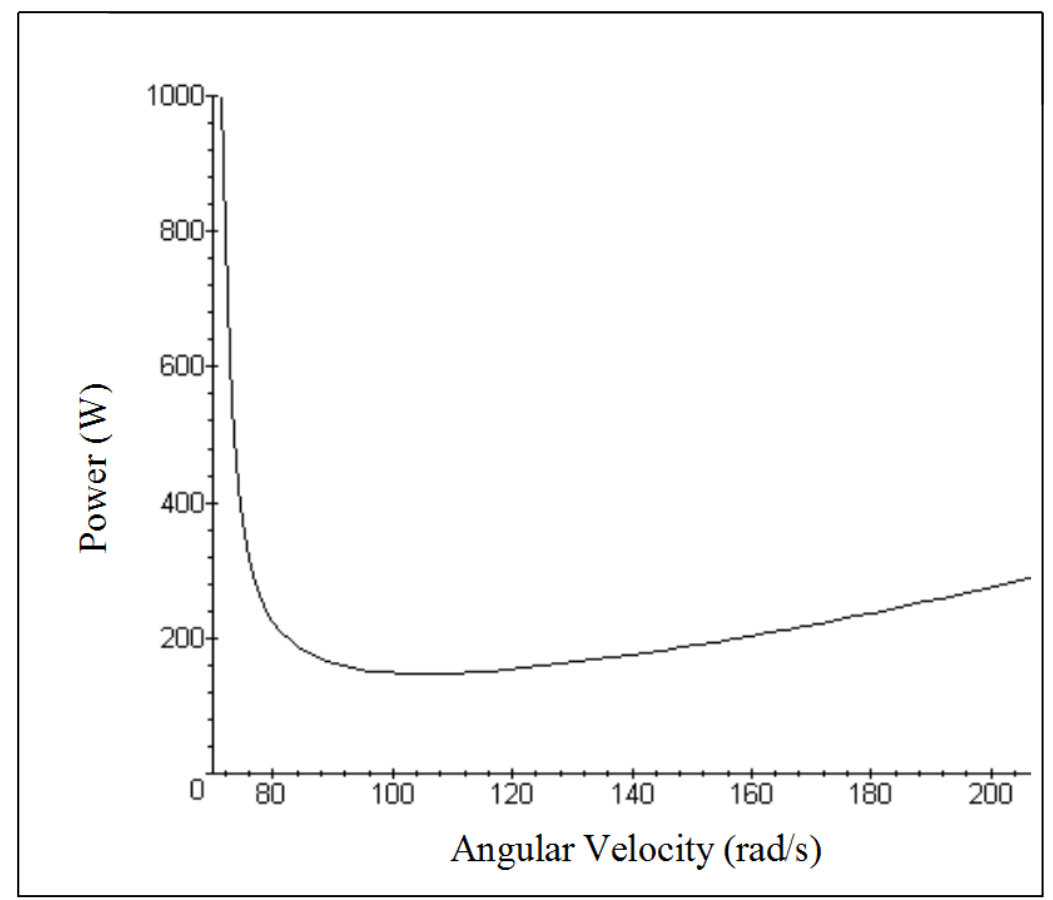

Figure 7. Power vs. maximum angular velocity

Equation

(7) is plotted in Figure 7. The minimum power requirement will be given by solving

$$
\frac{\partial P}{\partial \omega}=\frac{I_{\text {TOTAL }} \cdot \omega^{2}[3(\omega t-\theta)-t]}{(\omega t-\theta)}=0
$$

The root of this expression occurs at $\omega=104.71 \mathrm{rad} / \mathrm{s}$ for the warp knitting patterning system (see Figure 8 ). The minimum Power required is $\mathrm{P}=61 \mathrm{~W}$. Fixing the value of $\omega$ will in turn fix the values of $t_{a c c}, \alpha$ and $\mathrm{T}$ for the system. 


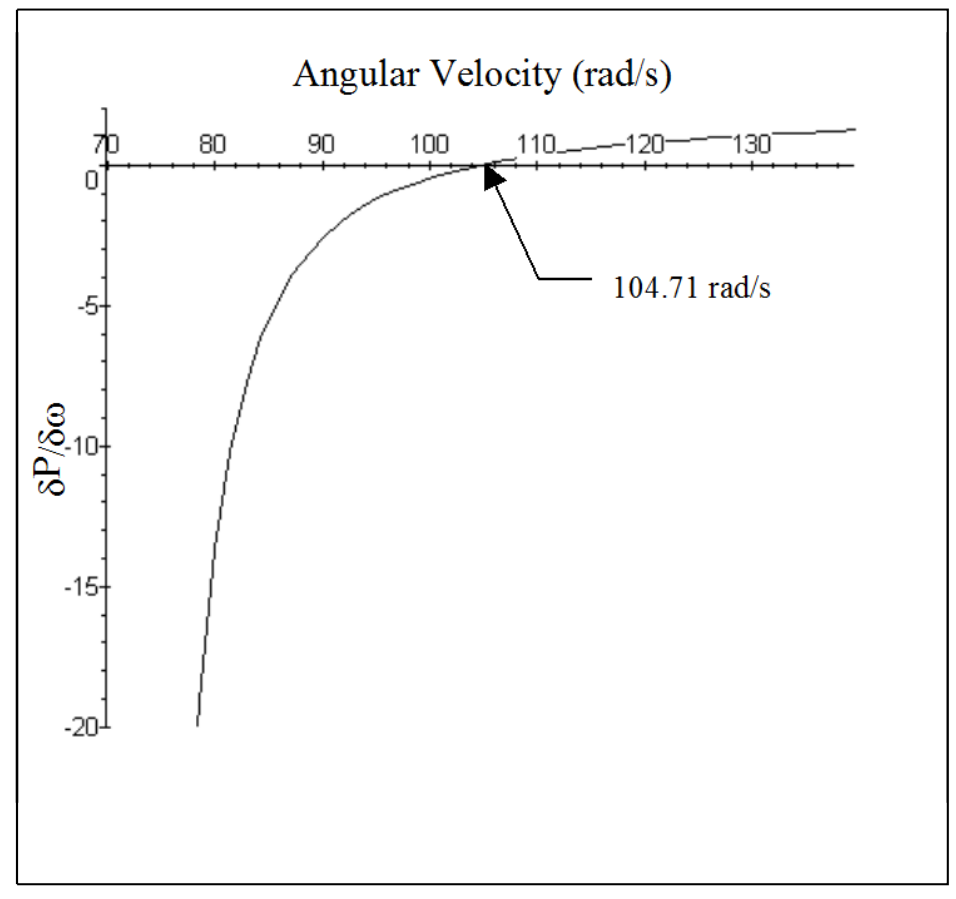

Figure 8. Minimum power requirement.

Selecting a servomotor for these values will ensure that the motions can be performed in the most efficient way.

\section{Motor Response}

Although the selection process ensures that the motor has sufficient power to accelerate the load in the calculated $t_{\mathrm{acc}}$, the motor response might not be fast enough to achieve the motion required within the specified time.

It was therefore necessary to carry out tests on two of the servo drives to ensure that they were capable of reacting as fast as was necessary. Two servomotorsmotors were selected. For the purpose of this paper they will be refered to as Motor A and Motor B. The specification given by the respective manufacturers is summarised in Table 1 
Table 1. Specifications of Two Servomotors Considered

\begin{tabular}{|l|c|c|}
\hline & Motor A & Motor B \\
\hline Rated Output Power (W) & - & 400 \\
\hline Rated Torque (N-m) & 1.47 & 1.30 \\
\hline Rated Speed (rpm) & - & 3000 \\
\hline Maximum Speed (rpm) & 7000 & 5000 \\
\hline Rated rms Current (A) & 2.1 & 2.5 \\
\hline Peak Current (A) & 8.0 & 10.5 \\
\hline Rotor Inertia (Kg-m $\left.{ }^{2}\right)$ & $4.7 \times 10^{-5}$ & $3.7 \times 10^{-5}$ \\
\hline Mechanical Time Constant (ms) & 1.00 & 0.47 \\
\hline Electrical Time Constant (ms) & 1.4 & 3.9 \\
\hline Torque Constant (Nm/A) & 0.73 & 0.36 \\
\hline Voltage Constant ( $\left.\mathrm{V}_{\text {rms }} / \mathrm{krpm}\right)$ & 44.6 & - \\
\hline Resistance ( $\Omega$ ) & 11.6 & 1.1 \\
\hline Inductance (mH) & 24.8 & 4.3 \\
\hline
\end{tabular}

Both motors and recommended motion controllers/drives were tested with and without load and the results differ greatly. While motor A responds to a step velocity input, with time to maximum velocity set to zero, Motor B follows a different control loop were the velocity is corrected every millisecond. Therefore, the only valid comparison that can be made from the graphs is the minimum time each motor requires to perform a given rotation. . Figure 9 shows the best response of the respective motors without any load. Motor B could perform the motion in a minimum of $13.15 \mathrm{~ms}$, that is, accelerating in 6.5ms. Motor A, on the other hand, was still impressive, performing the motion in a minimum of $21 \mathrm{~ms}$. 


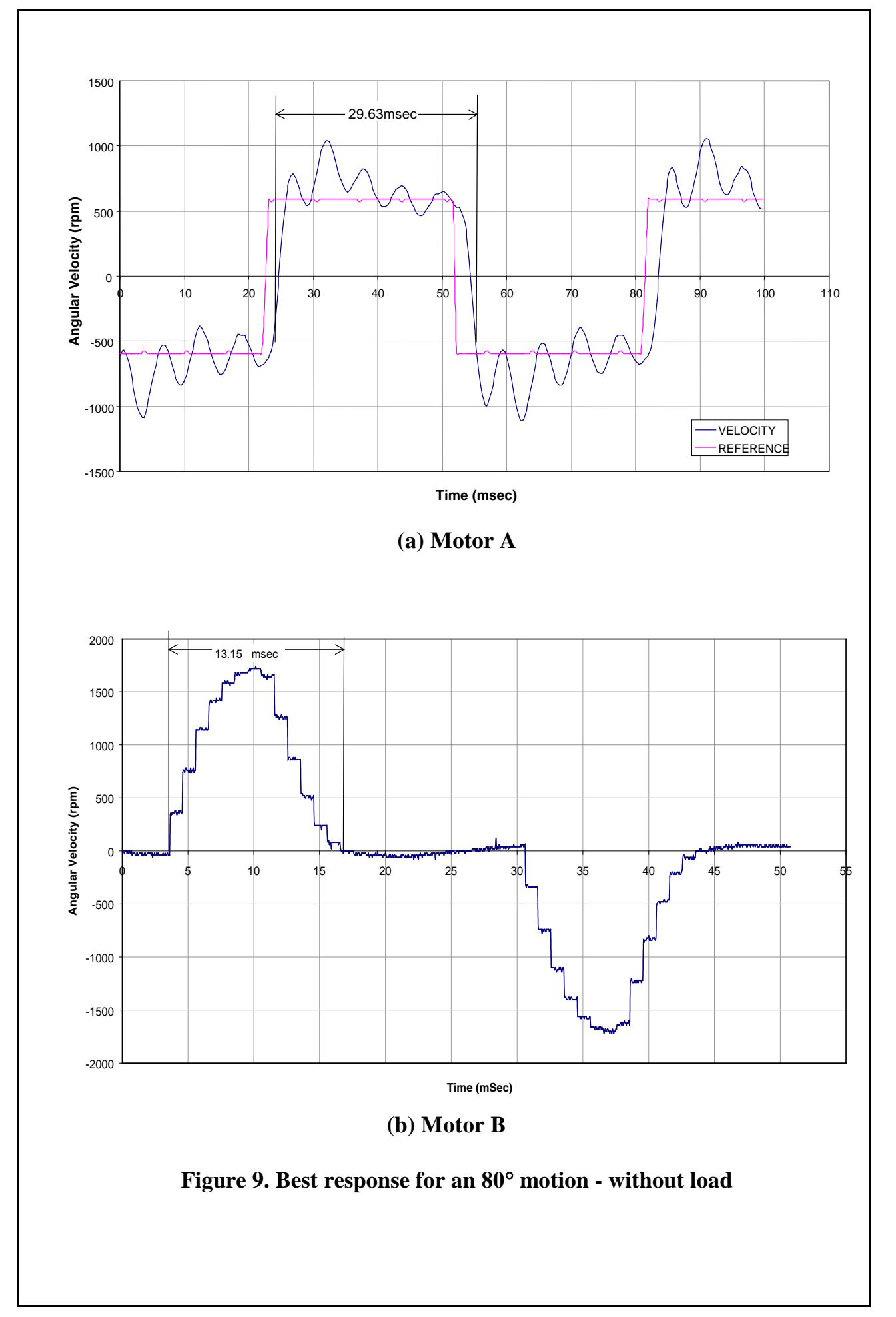


The only variable given by the manufacturers related to fast response is the mechanical time constant, defined as the time required for a motor to reach 63.2 percent of its rated speed or as;

$$
\tau_{m}=\frac{J \cdot R}{K_{E} \cdot K_{T}},
$$

where, $\quad J=$ Motor moment of inertia,

$R=$ Armature resistance,

$K_{E}=$ Voltage constant,

$K_{T}=$ Torque constant.

The mechanical time constant is lower in the for motor B (Table 1). However, according to the constant for that motor, 1740rpm should be reached in $0.43 \mathrm{~ms}$ rather than the $6 \mathrm{~ms}$ it actually needed during the test. We can only conclude, therefore, that a low mechanical time constant is desirable in a fast response system, but that it does not relate exactly to the practical results.

The difference in the performance is probably related to the difference in the mechanical construction of the two motors as well as the control algorithms used. In the case of Motor A system, proportional, velocity and acceleration feed forward gains were needed to obtain the best response shown in Figure 9 (a), while Motor B showed its best performance when only the proportional gain was set to $60 \%$.

Motor B, which gave a better response without load, was then tested with a disc manufactured to simulate the same reflected inertia as the real system would have. This simplified test method ensures that the motor can respond within the required time in frictionless system. It does not take into account the load created by the varying tension of the yarns as the motor is moving to position them near the required needle.

The patterning mechanism for the knitting machine was then designed, built and tested. It consists of three rings each controlled by servomotors. See Figure 10. The motors are only linked to the load by pulleys and belts, ensuring an appropriate gear ratio. The mechanism is no longer restricted by mechanical properties of the linkages, nor does it convert translational motion into rotational motion of a ring.

The mechanism was tested without yarns and the maximum rotation $\left(80^{\circ}\right)$ was 
achieved repeatably, alternating direction, in the specified time of $20 \mathrm{~ms}$. Each $80^{\circ}$ motion is equivalent accelerating from zero to $139 \mathrm{rpm}$ in $10 \mathrm{~ms}$ and decelerating to zero again in the remaining $10 \mathrm{~ms}$, which illustrates the very fast response of the system.

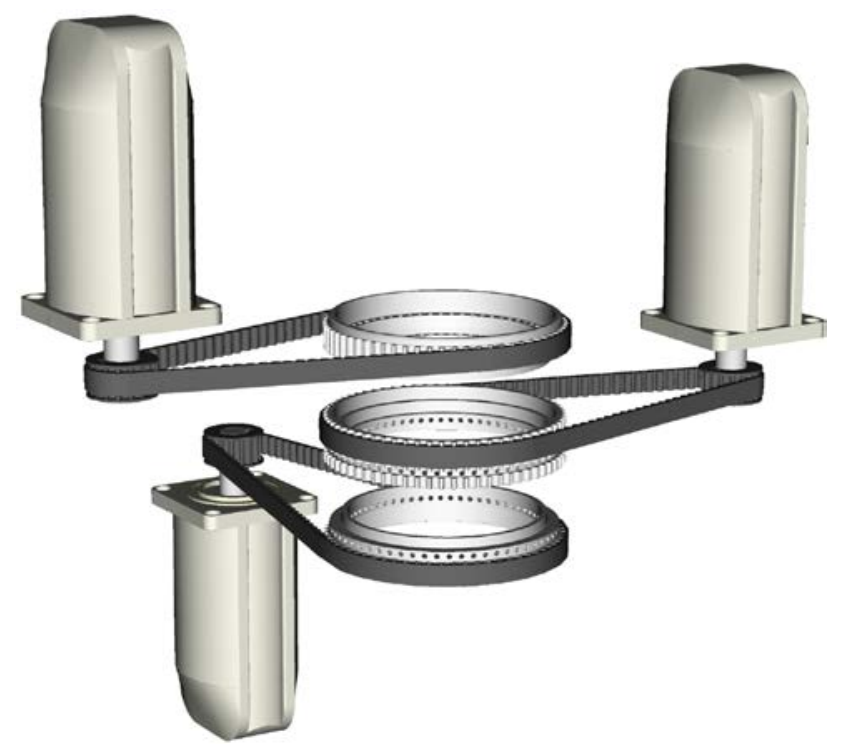

Figure 10. Servomotor Controlled Patterning Mechanism.

In addition, changing the knitting pattern can easily be done by entering a new set of values into the motion controller memory and involves no changes of mechanical parts.

The development of a new knitting pattern is reduced to stepping the motor until it reaches the desired position for each motion and recording those values. It no longer requires milling a new cam and it can involve as much iteration as necessary.

Moreover, the number of steps in a pattern is only restricted by memory capabilities of the motion controller. A pattern can reach hundreds of steps while the mechanical design has only used cams with up to 12-step patterns. 


\section{Conclusion}

The paper presents a mechatronic solution to the problem of designing a patterning mechanism for a circular warp knitting machine. The mechanical solution proposed (using an enclosed cam-track and cycloidal displacement profiles for each segment of the pattern) represents significant improvements on the existing mechanical design concepts.

The servo-controlled mechatronic design, however, is an entirely new concept. It requires very fast responses and uses AC brushless servomotors to control three patterning rings via a belt and pulley arrangement. Not only does it make the pattern capabilities significantly better than any mechanical system, it also meets the response requirements that will allow the machine to be run at $1000 \mathrm{rpm}$.

Both mechanisms have been manufactured and tested on separate machines, and are now commercially available.

The paper also puts forward a method for the selection of servomotors. Based on minimising the power required to perform the fastest motion required by the application, it ensures the selection of the smallest servomotor suitable for the application. This is very significant as it minimises the cost of the system: servomotor power capabilities determine its frame size, which in turn governs its cost.

\section{Acknowledgements}

This work was financially supported by a Teaching Company Scheme between Loughborough University and Tritex International Limited. The Teaching Company Directorate and Tritex International Limited being the contributors to the scheme.

The authors want to thank the Mechanical Engineering Department at Loughborough University and Tritex International Limited for the continuous technical support.

\section{References}

Beaven RW., et al (1995), The application of Setpoint Gain Scheduling to High-Speed Independent Drives. Control Eng. Practice, Vol. 3, pp 1581-1585, Pergamon 1995.

Borenstein M (1986), Rundstrickmaschine, European Patent, Pat No. 0200 094, Filed 05.11.1986 Tel Aviv, Israel. 
Erdman A G, Sandor G N (1991), Mechanism Design. Analysis and Synthesis. Vol. 1, $2^{\text {nd }}$ Edition, 1991, pp. 343-410.

Iwasaki T. et al (1996), Auto-Tuning of two-Degree-of-Freedom Motor Control for High-Accuracy Trajectory Motion, Control Eng. Practice, Vol. 4, No. 4, pp. 537-544, Pergamon 1996.

Ragosa I Vyacheslavovich (1990), Circular Warp Knitting Machine, UK Patent, No. 2 039544 A, 20 November, 1990.

Yao, Yan-an et al (2000), Motion Control of Cam Mechanisms, Mechanisms and Machine Theory, Volume 35, Issue 4, April 2000, PP 593-607. 